\title{
Efeito da sazonalidade e disponibilidade de recursos sobre comunidades microbianas em solo de floresta de eucalipto
}

\author{
Effect of seasonality and resource availability on microbial communities in \\ soil of Eucalyptus forest
}

\author{
Julio Cesar Delvaux ${ }^{1}$, Paulo Sérgio Balbino Miguel $^{2}$ (1), Marcelo Nagem Valério de Oliveira ${ }^{3}$ (1), \\ Miguel Henrique Rosa Franco ${ }^{4}$ (D), Reginaldo de Camargo 4 (D), Arnaldo Chaer Borges ${ }^{5}$ (1) \\ ${ }^{1}$ Instituto Federal de Educação, Ciência e Tecnologia do Triângulo Mineiro - IFTM Ituiutaba, Campus Ituiutaba, Ituiutaba, MG, \\ Brasil \\ 2Instituto Federal de Educação, Ciência e Tecnologia Roraima, Campus Amajari, Amajari, RR, Brasil \\ ${ }^{3}$ Departamento de Ciências Básicas da Vida, Universidade Federal de Juiz de Fora, Campus Governador Valadares - UFJF, \\ Campus Governador Valadares, Governador Valadares, MG, Brasil \\ ${ }^{4}$ Instituto de Ciências Agrárias - ICIAG, Universidade Federal de Uberlândia - UFU, Uberlândia, MG, Brasil \\ ${ }^{5}$ Departamento de Microbiologia - DMB, Universidade Federal de Viçosa - UFV, Viçosa, MG, Brasil
}

Como citar: Delvaux, J. C., Miguel, P. S. B., Oliveira, M. N. V., Franco, M. H. R., Camargo, R., \& Borges, A. C. (2021). Efeito da sazonalidade e disponibilidade de recursos sobre comunidades microbianas em solo de floresta de eucalipto. Scientia Forestalis, 49(130), e3593. https://doi.org/10.18671/scifor.v49n130.18

\section{Resumo}

O eucalipto ocupa posição de destaque no setor florestal brasileiro em razão do seu rápido crescimento e adaptabilidade às diversas condições edafoclimáticas, e das características tecnológicas da madeira. O presente trabalho teve como objetivo determinar a influência da sazonalidade e da interrupção do fluxo de fotoassimilados da parte aérea para a rizosfera, pelo anelamento de árvores, sobre a estrutura da comunidade microbiana do solo. O estudo foi conduzido em duas fases de crescimento pós-plantio em florestas de eucalipto na região do Vale do Rio Doce, Minas Gerais, Brasil, áreas sob domínio do Bioma Mata Atlântica. O índice de diversidade de Shanon $(H)$ variou de 1,7 a 3,5 considerando os domínios, Bacteria, Archaea e Eukarya, nas duas fases de crescimento pós-plantio e mostrou que a fase de crescimento não afeta a diversidade microbiana. A avaliação dos perfis de eletroforese em gel com gradiente desnaturante (DGGE) revelou, pelo método de agrupamento médio entre grupos (UPGMA), a tendência de agrupamento dos perfis das amostras coletadas nas diferentes épocas de amostragem (início do período chuvoso, chuvoso e seco) e, em menor escala, o agrupamento das amostras coletadas nos habitats da rizosfera e da não rizosfera em áreas com plantas aneladas e não aneladas, o que foi atribuído à capacidade da planta em moldar a estrutura da comunidade microbiana na rizosfera. A variação dos perfis de DGGE dentro de gradiente sazonal mostra que a sazonalidade e o aporte de fotoassimilados para a rizosfera determinaram a estrutura da comunidade microbiana.

Palavras-chave: DGGE; Eucalyptus urograndis; Rizosfera.

\footnotetext{
Abstract
}

Eucalyptus occupies a prominent position in the Brazilian forestry sector due to its rapid growth and adaptability to diverse soil and climatic conditions, and the technological characteristics of wood. The present study had as objective to determine the influence of the seasonality and the interruption of the photoassimilates flow from the aerial part to the rhizosphere, by the girdling of trees, on the structure of the microbial community of the soil. The study was conducted in two

Fonte de financiamento: Celulose Nipo-Brasileira.

Conflito de interesse: Nada a declarar.

Autor correspondente: juliodelvaux@iftm.edu.br

Recebido: 16 agosto 2020.

Aceito: 16 setembro 2020.

Editor: Paulo Henrique Müller Silva.

(c) (i) Este é um artigo publicado em acesso aberto (Open Access) sob a licença Creative Commons Attribution, que permite uso, distribuição e cc) reprodução em qualquer meio, sem restrições desde que o trabalho original seja corretamente citado. 
phases of post-planting growth in Eucalyptus forests in the Vale do Rio Doce region, Minas Gerais, Brazil, areas within the Atlantic Forest Biome. The diversity index of Shanon $(\mathrm{H})$ varied from 1.7 to 3.5 considering the domains, Bacteria, Archaea and Eukarya, in the two stages of post-planting growth and showed that growth phase does not affect microbial diversity. The evaluation of the gel electrophoresis profiles with denaturing gradient (DGGE) revealed by the method of grouping between groups (UPGMA) the tendency of grouping the profiles of the samples collected at different sampling times (beginning of the rainy, rainy and dry season) and, to a lesser extent, the grouping of the samples collected in the habitats rhizosphere and non-rhizosphere in areas with girdling and non- girdling plants which was attributed to the plant's ability to shape the structure of the microbial community in the rhizosphere. The variation of DGGE profiles within the seasonal gradient shows that the seasonality and the contribution of photoassimilates to the rhizosphere determined the structure of the microbial community.

Keywords: DGGE; Eucalyptus urophylla x E. grandis; Rhizosphere.

\section{INTRODUÇÃO}

A presença da madeira ao longo do curso da história humana revela seu valor entre as principais matérias primas que sustentam a vida no planeta. A diversificação do seu uso, a demanda crescente e a oferta natural cada vez mais escassa induziram as mudanças culturais e tecnológicas necessárias à sua obtenção, da forma extrativista, para a de cultivo de plantas com alto potencial produtivo e adaptadas a cultivo em grandes empreendimentos florestais (Instituto Brasileiro de Árvores, 2019). Nos trópicos o eucalipto é a espécie florestal mais cultivada, representando a principal fonte para a produção de madeira e celulose de fibra curta no Brasil (Silverio et al., 2007; Stape et al., 2010; Instituto Brasileiro de Árvores, 2019).

Em florestas de eucalipto as árvores aportam ao solo grandes quantidades de carbono e nitrogênio na forma de resíduos (folhas, galhos e raízes mortas) e de exsudatos radiculares (Fontaine et al., 2004; Jackson et al., 2008; Yarwood et al., 2009; Yin et al., 2014). A presença desses compostos na rizosfera influencia o complexo habitat composto por ampla diversidade de organismos e as suas interações em diversos níveis (Bais et al., 2006; Barret et al., 2011).

A matéria orgânica acumulada no solo, juntamente com os exsudatos radiculares, representam a principal fonte de energia para os micro-organismos que promovem a ciclagem da matéria orgânica e, por isso, exercem papel chave nos ciclos do carbono e do nitrogênio (Buckley \& Schmidt, 2002). Como a maior parte do carbono disponível para os micro-organismos do solo é derivada da fotossíntese, os processos ou fatores que a influenciam também afetam a alocação de carbono para a parte aérea e raízes e, consequentemente, a atividade e a composição da comunidade microbiana (Jackson et al., 2008).

É sabido que fatores sazonais, tais como a disponibilidade hídrica, influenciam diretamente a transferência subterrânea de carbono e nitrogênio realizada pelas árvores e por processos microbianos. Especificamente, afetam diretamente a fisiologia das árvores, principalmente a fotossíntese e a rizodeposição (Compant et al., 2010; Rasche et al., 2011).

O transporte do carbono fixado pela fotossíntese para o solo ocorre via floema, além da deposição do material vegetal e da decomposição de raízes mortas (Wardle, 1992; Jackson et al., 2008). A introdução de fotoassimilados no solo via exsudação radicular representa importante fonte de compostos de carbono prontamente assimiláveis para a microbiota, sendo um dos principais fatores que determinam a presença e a atividade da comunidade microbiana na rizosfera (Yarwood et al., 2009; Chen et al., 2010).

O balanço energético do sistema solo-planta pode ser alterado em florestas plantadas pelo uso da técnica de anelamento da árvore, como forma de interromper o fluxo de fotoassimilados da parte aérea para a rizosfera, para permitir o estudo do comportamento da comunidade microbiana do solo sem perturbação desse 
ecossistema (Högberg \& Read, 2006; Chen et al., 2010). No Brasil, não foram encontrados relatos de estudos com a utilização do anelamento para estudo da estrutura da comunidade microbiana em solos de florestas plantadas com eucalipto

Os estudos sobre a diversidade de micro-organismos do solo, sua composição e funcionamento, são complexos em razão da heterogeneidade física, química e biológica dos solos e, também, das relações entre a quantidade de espécies e a abundância de micro-organismos (Daniel, 2005).

A diversidade microbiana pode ser representada em termos ecológicos e moleculares considerando o número e a distribuição de sequências distintas presentes no DNA extraído diretamente da comunidade microbiana de um determinado habitat (Garbeva et al., 2004). A sua quantificação é de importância em análises de fenômenos como sucessão, colonização e resposta a distúrbios antrópicos ocorridos em determinado ambiente.

Autores destacam que são poucos os estudos em que se avalia a estrutura da comunidade microbiana do solo sob floresta de eucalipto (Cao et al., 2010). Assim, o objetivo do presente trabalho foi o de determinar a influência da sazonalidade e da interrupção do fluxo de fotoassimilados da parte aérea para a rizosfera, pelo anelamento de árvores em duas fases de crescimento pós-plantio, sobre a estrutura comunidade microbiana do solo em florestas de eucalipto.

\section{MATERIAL E MÉTODOS}

As áreas experimentais foram demarcadas na região do Vale do Rio Doce, Minas Gerais, Brasil, cultivadas com Eucalyptus urophylla x E. grandis. Foram implantadas quatro parcelas de $81 \mathrm{~m}^{2}$ cada, duas contendo árvores com 18 meses de crescimento pós-plantio no município de Catas Altas - MG (Projeto Catas Altas I) e outras duas com 72 meses no município de Santa Bárbara - MG (Projeto Serra do Pinho). Nas duas regiões predominam solos altamente intemperizados, de baixa fertilidade natural e com relevo movimentado, de ondulado a forte ondulado. A classe de solo mais representativa é Latossolo Amarelo (Tabelas 1 e 2). A temperatura média anual é $21,6^{\circ} \mathrm{C}$ e a precipitação média anual de 122,9 mm (Tabela 3).

Tabela 1. Características das áreas e dos povoamentos de eucalipto estudadas

\begin{tabular}{ccccccc}
\hline Projeto & Lat. (w) & Long. (s) & $\begin{array}{c}\text { Altitude } \\
(\mathbf{m})\end{array}$ & Solo & Implantação & $\begin{array}{c}\text { Produtividade } \\
\text { ( }^{\mathbf{3}} \mathbf{h a}^{-1} \mathbf{)}\end{array}$ \\
\hline Catas Altas I & $43^{\circ} 24^{\prime} 54^{\prime \prime}$ & $19^{\circ} 57^{\prime} 32^{\prime \prime}$ & 750 & LAd1 & 1970 & 340 \\
Serra do Pinho & $43^{\circ} 24^{\prime} 28^{\prime \prime}$ & $20^{\circ} 4^{\prime} 30^{\prime \prime}$ & 740 & LAw2 & 1989 & 340 \\
\hline
\end{tabular}

Tabela 2. Características químicas e físicas dos solos das áreas e dos povoamentos de eucalipto estudadas

\begin{tabular}{|c|c|c|c|c|c|c|c|c|c|}
\hline Projeto & pH & $\mathbf{P}$ & $\mathbf{K}$ & $\mathrm{Ca}^{2+}$ & $\mathrm{Mg}^{2+}$ & $\mathrm{Al}^{3+}$ & MO & Prem & $\mathbf{N}$ \\
\hline & $\mathrm{H}_{2} \mathrm{O}$ & \multicolumn{2}{|c|}{$-\mathrm{mg} / \mathrm{dm}^{3}$} & \multicolumn{3}{|c|}{ - $\mathrm{cmol}_{\mathrm{c}} / \mathrm{dm}^{3}$} & dag/Kg & $\mathrm{mg} / \mathrm{L}$ & dag/Kg \\
\hline Catas Altas I & 5,61 & 13,6 & 135 & 0,92 & 0,35 & 0,40 & 2,90 & 26,9 & 0,12 \\
\hline Serra do Pinho & 5,45 & 2,5 & 58 & 0,69 & 0,16 & 0,70 & 2,63 & 20,3 & 0,10 \\
\hline
\end{tabular}

Tabela 3. Histórico de precipitação na área estudada durante o período experimental

\begin{tabular}{|c|c|c|c|c|c|c|c|c|c|c|c|c|}
\hline \multirow{2}{*}{ Ano } & jan & fev & mar & abr & mai & jun & jul & Ago & set & out & nov & dez \\
\hline & \multicolumn{12}{|c|}{ 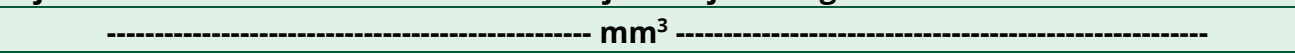 } \\
\hline 2011 & 243,0 & 123,4 & 329,5 & 93,7 & 21,3 & 8,9 & 1,8 & 1,0 & 8,9 & 231,4 & 431 & 664,2 \\
\hline 2012 & 382,3 & 28,7 & 166,1 & 21,8 & 138,6 & 16,5 & 0,0 & 5,3 & 36,8 & - & - & - \\
\hline
\end{tabular}


Na primavera de 2011, uma parcela de cada área teve suas árvores aneladas por remoção da casca em uma faixa de $20 \mathrm{~cm}$ ao redor do tronco a 1,0 m acima do solo (Högberg et al., 2001), de forma a interromper o fluxo de fotoassimilados para a rizosfera (Figura 1A). Uma parcela controle, sem anelamento foi mantida em cada área. Toda vegetação de sub-bosque e as brotações na região inferior das árvores foram removidas semanalmente durante todo período experimental.
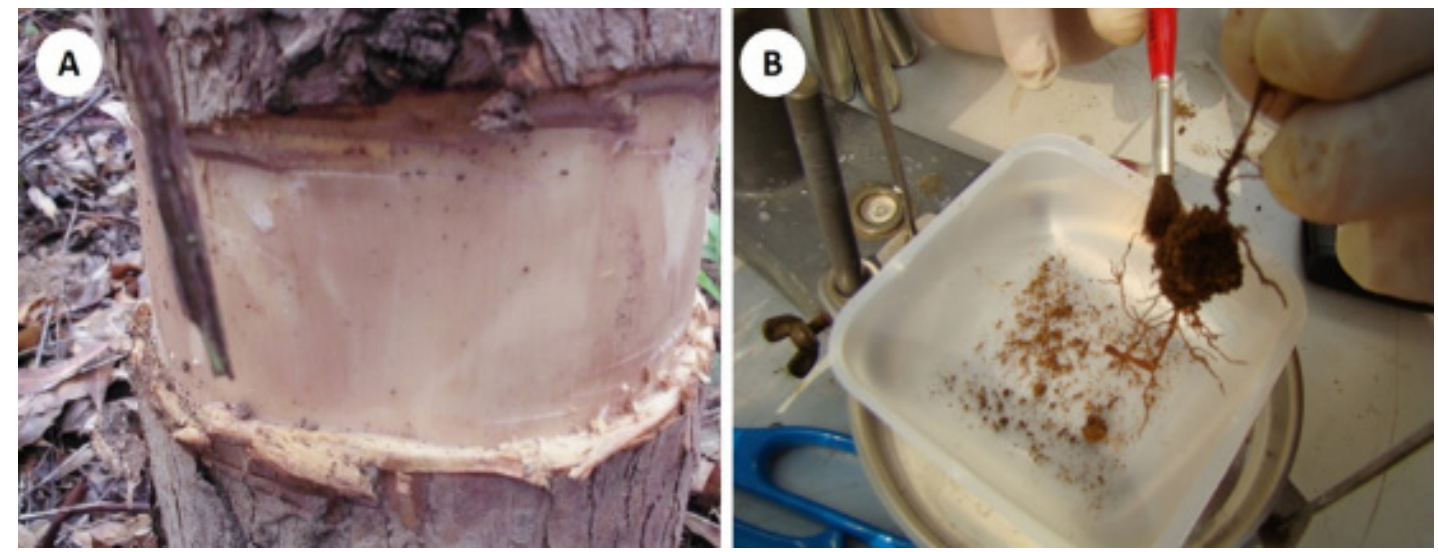

Figura 1. A: Anelamento das árvores de eucalipto. B: Coleta do solo rizosférico

As amostras de $500 \mathrm{~g}$ de solo da camada de $0-10 \mathrm{~cm}$ foram coletadas no entorno da árvore central de cada bloco, estabelecendo-se o raio médio de coleta de maneira a interceptar a zona de crescimento de raízes finas, próximas à superfície do solo. O solo rizosférico foi removido das raízes finas com pincel esterilizado e recolhido em recipientes de polipropileno previamente esterilizados (Figura 1B). A extração do DNA das populações microbianas do solo foi realizada utilizando-se do PowerSoil ${ }^{\circledR}$ DNA Isolation Kit (MoBio Laboratories Inc., Carlsbad, CA, USA), com modificações.

O DNA obtido foi utilizado como molde para amplificação de regiões do rDNA 16S de archeas e bactérias e regiões do rDNA 185 de fungos utilizando a estratégia de Nested-PCR, em que uma primeira PCR fornece amplicons que são usados como molde em uma segunda PCR (Tabela 4).

A separação dos diferentes amplicons em Eletrofore em Gel com Gradiente Desnaturante (DGGE) foi feita pela aplicação de $20 \mu \mathrm{L}$ dos produtos da segunda PCR em DGGE, sendo o gradiente ureia/formamida 40 a 55\% para bactérias e archeas e de 35 a $55 \%$ para fungos. A eletroforese foi conduzida em temperatura de $60^{\circ} \mathrm{C}$ e voltagem constante de $60 \mathrm{~V}$ durante 20 horas, em equipamento DCode ${ }^{T M}$ Universal Mutation Detection System (BIO-RAD -, CA, USA), seguindo as recomendações do fabricante. O gel foi corado com SYBRß Gold (Invitrogen, Carlsbad, CA, USA).

Os dados obtidos das análises de atividade, riqueza e diversidade microbiana foram avaliados com o auxílio do ASSISTAT - Assistência Estatística (Silva, 2012). Os índices de riqueza (R) e diversidade de Shannon $(\mathrm{H})$ foram calculados com a utilização do software PAST (Hammer, 2012) a partir das matrizes de presença e ausência geradas da análise dos perfis de DGGE no programa Bionumerics versão 6.0 (Applied Maths, Kortrijk, Belgium). A estrutura da comunidade microbiana foi avaliada com base no coeficiente Dice de similaridade e no método de UPGMA (Unweighted Pair Group Method with Arithmetic) para análise dos agrupamentos utilizando o programa Bionumerics (Applied Maths). Para elaboração dos diagramas de Venn foi utilizado o software MOTHUR v.1.23.0 (Schloss et al., 2009). 
Tabela 4. Descrição dos primers, reagentes e detalhes da amplificação utilizados para PCR-DGGE das comunidades microbianas no solo.

\begin{tabular}{|c|c|c|c|c|c|c|c|c|c|c|}
\hline \multirow[b]{2}{*}{$\begin{array}{l}\frac{2}{2} \\
\frac{1}{5}\end{array}$} & \multirow[b]{2}{*}{ 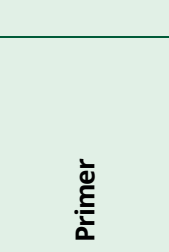 } & \multicolumn{9}{|c|}{ Condições da PCR-DGGE } \\
\hline & & 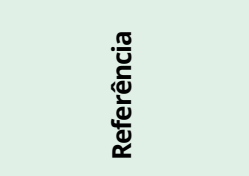 & 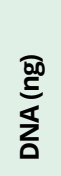 & $\begin{array}{l}\underset{\sigma}{\sigma} \\
\underset{\leftarrow}{\infty}\end{array}$ & 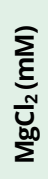 & 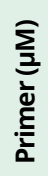 & $\begin{array}{l}\sum_{\bar{z}} \\
0 \\
\text { 克 } \\
0\end{array}$ & 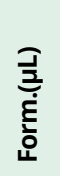 & 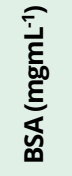 & 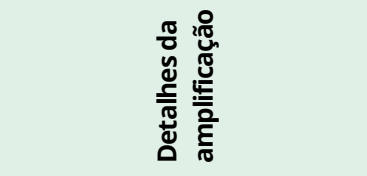 \\
\hline \multirow{2}{*}{ 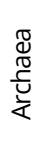 } & $\begin{array}{l}\mathrm{ARCH} 344 \mathrm{f} \\
927 \mathrm{r}\end{array}$ & $\begin{array}{l}\text { Raskin, et al. (1994) } \\
\text { Jurgens, et al. (1997) }\end{array}$ & 30 & 2 & 5 & 5 & 200 & - & - & $\begin{array}{l}94^{\circ} \mathrm{C} 5 \mathrm{~min}-(10 \mathrm{x}): 94^{\circ} \mathrm{C} 30 \mathrm{~s} \\
61-56^{\circ} \mathrm{C} 30 \mathrm{~s}-72^{\circ} \mathrm{C} 1 \mathrm{~min}\end{array}$ \\
\hline & $\begin{array}{c}\text { ARCH } 344 f G C \\
517 r\end{array}$ & Lane et al. (1985) & 30 & 1.25 & 3 & 5 & 200 & 0.5 & 12.5 & $\begin{array}{c}\text { (30x): } 94{ }^{\circ} \mathrm{C} 30 \mathrm{~s}-56^{\circ} \mathrm{C} 30 \mathrm{~s}-72 \\
{ }^{\circ} \mathrm{C} 1 \mathrm{~min}-72^{\circ} \mathrm{C} 7 \mathrm{~min}\end{array}$ \\
\hline \multirow{2}{*}{ 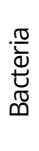 } & $\begin{array}{l}\text { P027 } \\
1492 r\end{array}$ & Deng et al. (2007) & 20 & 2 & 3 & 5 & 200 & - & 6.7 & $94^{\circ} \mathrm{C} 4 \mathrm{~min}-(35 \mathrm{x}): 94^{\circ} \mathrm{C} 30 \mathrm{~s}$ \\
\hline & $\begin{array}{l}\text { U968GC } \\
1492 r\end{array}$ & Favier et al. (2002) & 20 & 1.25 & 3 & 5 & 200 & 0.5 & 6.7 & $\begin{array}{c}55^{\circ} \mathrm{C} 60 \mathrm{~s}-72^{\circ} \mathrm{C} 90 \mathrm{~s}-72^{\circ} \mathrm{C} 90 \\
\mathrm{~s} \min -72^{\circ} \mathrm{C} 7 \mathrm{~min}\end{array}$ \\
\hline \multirow{5}{*}{\begin{tabular}{l}
$\stackrel{8}{00}$ \\
\multirow{3}{7}{} \\
\end{tabular}} & NS1 & May et al. (2001) & & & & & & & & $\begin{array}{l}94^{\circ} \mathrm{C} 5 \mathrm{~min}-(35 \mathrm{x}): 94^{\circ} \mathrm{C} 1 \mathrm{~min}- \\
47^{\circ} \mathrm{C} 1 \mathrm{~min}-72^{\circ} \mathrm{C} 2 \mathrm{~min}-\end{array}$ \\
\hline & EF3 & $\begin{array}{l}\text { Oros-Sichler et al. } \\
\qquad(2006)\end{array}$ & 20 & 2 & 3 & 5 & 200 & - & - & $72^{\circ} \mathrm{C} 10 \mathrm{~min}$ \\
\hline & FF390 & Vainio \& Hantula & 20 & 1.25 & 3 & 5 & 200 & - & - & $\begin{array}{c}94^{\circ} \mathrm{C} 5 \mathrm{~min}-(35 \mathrm{x}): 94{ }^{\circ} \mathrm{C} 1 \mathrm{~min}- \\
50^{\circ} \mathrm{C} 1 \mathrm{~min}-72^{\circ} \mathrm{C} 1 \mathrm{~min}-\end{array}$ \\
\hline & FR1GC & & & & & & & & & $72^{\circ} \mathrm{C} 10 \min$ \\
\hline & Grampo GC & Nubel et al. (1996) & & & & & & & & \\
\hline
\end{tabular}

Volume final: $25 \mu \mathrm{L}$.

\section{RESULTADOS E DISCUSSÃO}

O estudo do padrão de migração dos fragmentos de DNA em DGGE mostrou distintas UTOs de arqueias, bactérias e fungos nos solos analisados (Figuras 2, 3 e 4) e revelou a formação de grupos distintos entre as amostras coletadas no início do período chuvoso (C1 - 12/10/11), período chuvoso (C2 - 16/12/11) e período seco (C3 - 05/05/12), indicando que a disponibilidade de água foi o componente determinante na estruturação das comunidades microbianas no solo.

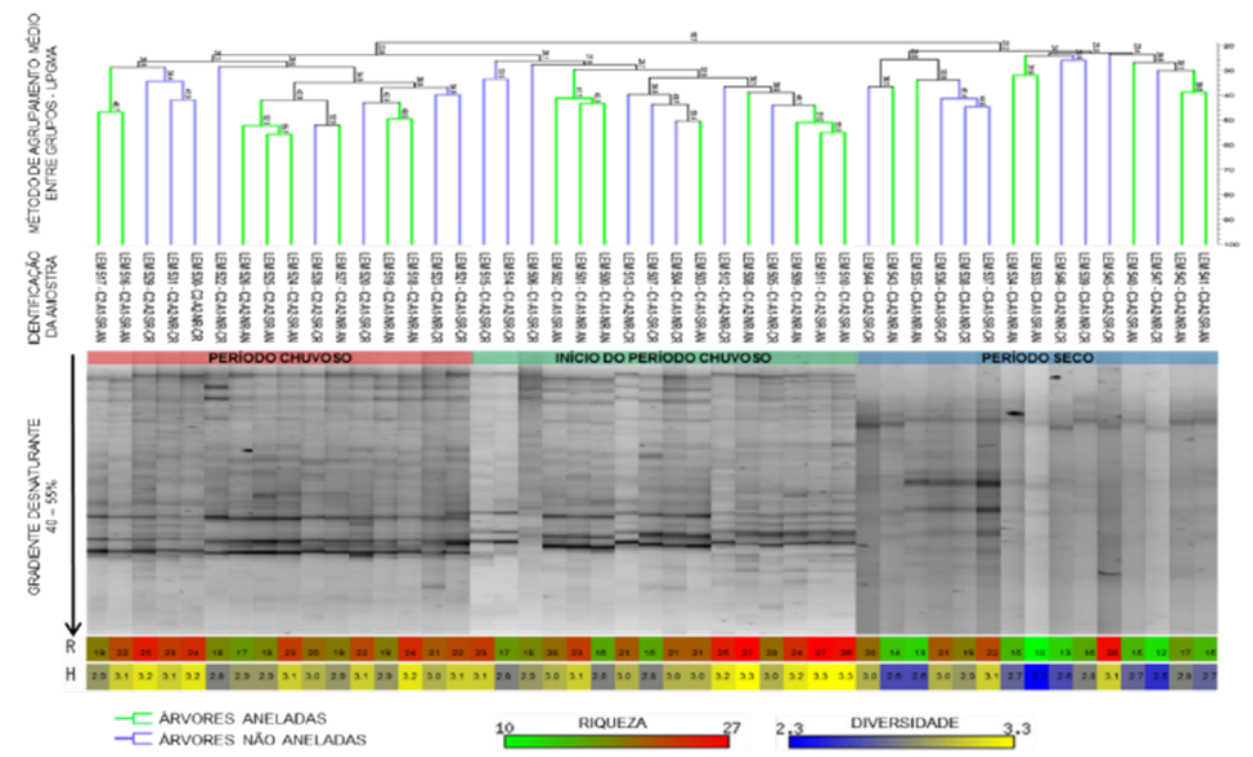

Figura 2. Perfis eletroforéticos em DGGE de fragmentos dos rDNAs 16S, Índices de Riqueza de UTOs (R) e Diversidade de Shannon $(\mathrm{H})$ detectados com base na separação de amplicons de rDNA 16S $(\mathrm{H})$ de comunidades de Archaea presentes em solos de florestas plantadas de Eucalipto na região do Vale do Rio Doce, Minas Gerais, Brasil. C1 - Coleta no início do período chuvoso (12/10/11); C2 - Coleta período chuvoso (16/12/12); C3 - Coleta

no período seco (02/05/12); A1 - Árvores com 18 meses de crescimento; A2 -Árvores com 72 meses de crescimento; NR - Solo não rizosférico; SR - Solo rizosférico; AN - Árvores Aneladas; CR - Árvores não aneladas. 


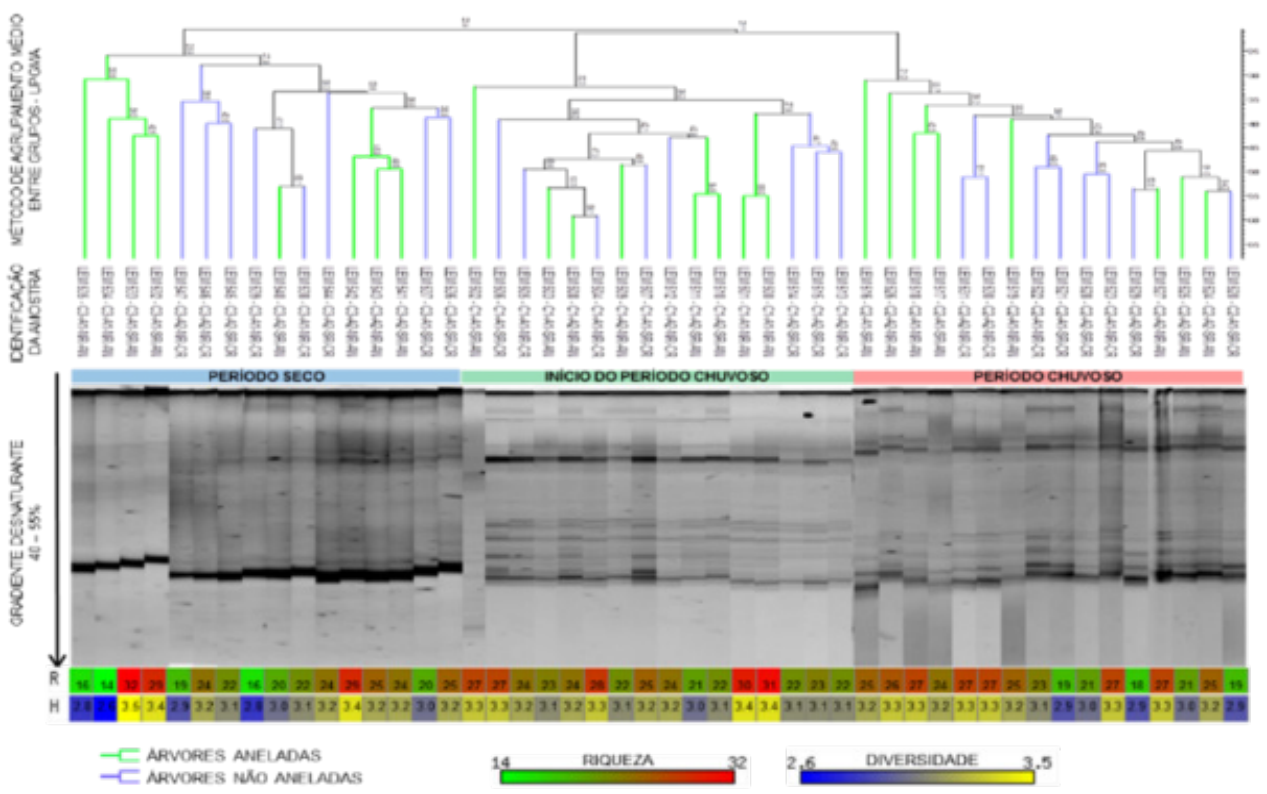

Figura 3. Perfis eletroforéticos em DGGE de fragmentos dos rDNAs 16S, índices de Riqueza de UTOs (R) e Diversidade de Shannon $(\mathrm{H})$ detectados com base na separação de amplicons de rDNA 16S de comunidades de Bacteria presentes em solos de florestas plantadas de Eucalipto na região do Vale do Rio Doce, Minas Gerais, Brasil. C1 - Início do período chuvoso (12/10/11); C2 - Período chuvoso (16/12/11); C3 - Período seco (05/05/12);

A1 - Árvores com 18 meses de crescimento; A2 -Árvores com 72 meses de crescimento; NR - Solo não rizosférico; SR - Solo rizosférico; AN - Árvores Aneladas; CR - Árvores não aneladas.

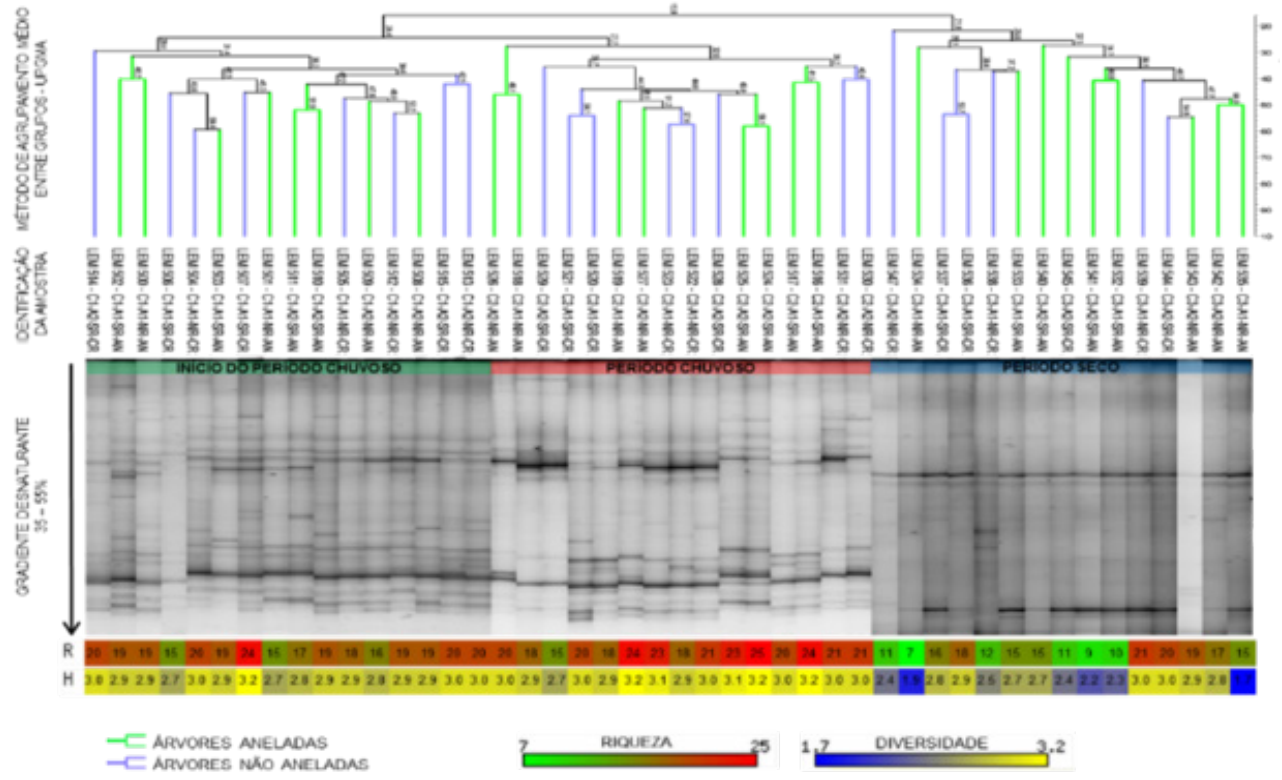

Figura 4. Perfis eletroforéticos em DGGE de fragmentos dos rDNAs 18S, índices de Riqueza de UTOs (R) e Diversidade de Shannon $(\mathrm{H})$ detectados com base na separação de amplicons de rDNA 18S de comunidades de fungos presentes em solos de florestas plantadas de Eucalipto na região do Vale do Rio Doce, Minas Gerais, Brasil C1 - Coleta no início do período chuvoso (12/10/11); C2 - Coleta período chuvoso (16/12/11); C3 - Coleta no período seco (02/05/12); A1 - Árvores com 18 meses de crescimento; A2 -Árvores com 72 meses de crescimento; NR - Solo não rizosférico; SR - Solo rizosférico; AN - Árvores Aneladas; CR - Árvores não aneladas.

A PCA permitiu a distribuição dos perfis das comunidades ao longo dos eixos de ordenação com base na presença e ausência de bandas detectadas por DGGE. O gráfico gerado da PCA explicou 63,7\%, 61,8\% e 43\% do comportamento das populações de arqueas, bactérias e fungos, respectivamente, em função dos períodos avaliados (Figura 5). 


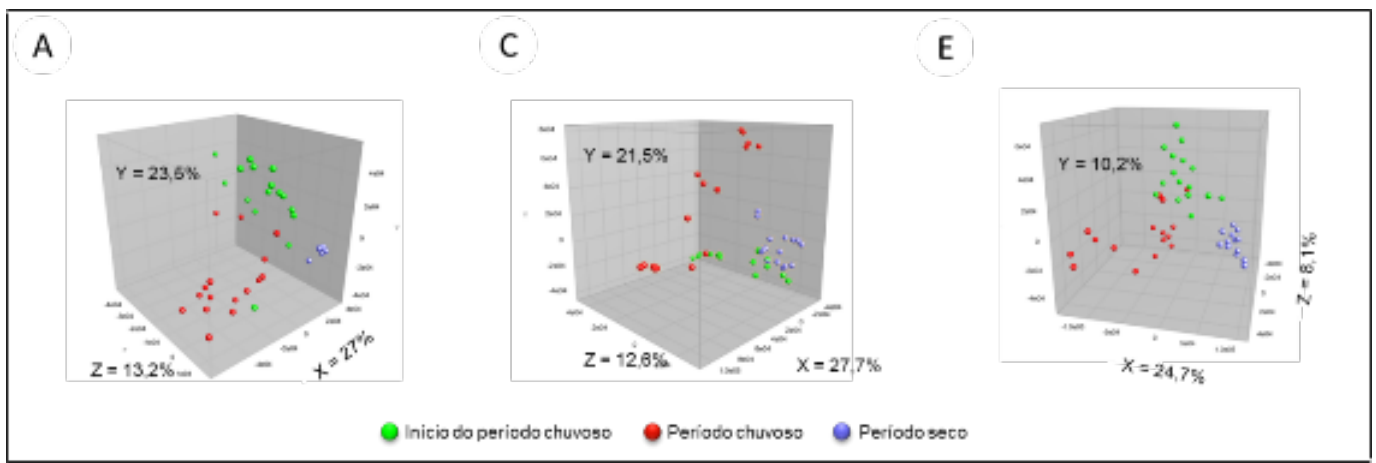

Figura 5. Análise de componentes principais (PCA) das comunidade de arqueas (2A), bactérias (2B) e fungos (2C). A ordenação considerou a presença e a ausência de amplicons de rDNA 16S de arqueas e bactérias e de rDNA $18 \mathrm{~S}$ de fungos.

As matrizes de presença e ausência geradas a partir dos perfis eletroforéticos da PCRDGGE evidenciaram clara variação no perfil das comunidades microbianas em função das épocas amostradas, e também que a maior parte das UTOs de archaeas, bactérias e fungos estão presentes em todos os períodos (Figura 6).

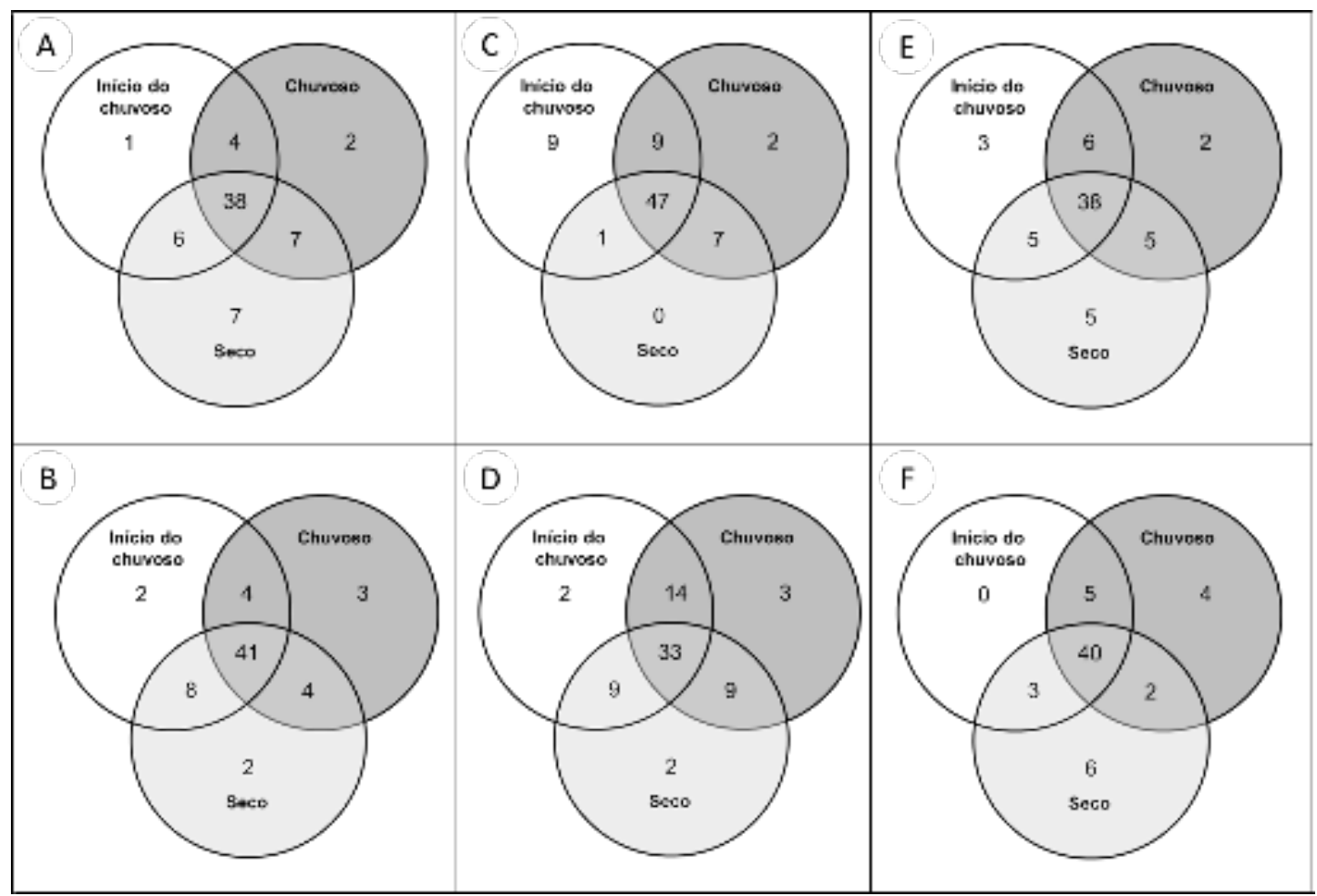

Figura 6. Comparação do número de UTOs de archeas nas áreas 1 (A) e 2 (B), bactérias nas áreas 1 (C) e 2 (D) e fungos nas áreas 1 (E) e 2 (F) encontradas no início do período chuvoso, chuvoso e seco.

A análise de cluster dos perfis de PCR-DGGE para os três domínios mostram pequena tendência de agrupamento das comunidades microbianas das árvores aneladas quando comparadas àquelas das árvores não-aneladas. O mesmo padrão foi observado para as comunidades de archeas, bactérias e fungos das amostras de solo rizosférico e não-rizosférico (Figuras 2, 3 e 4).

Os índices de riqueza $(R)$ e diversidade de Shannon $(H)$ das comunidades de archeas, bactérias e fungos (Tabelas 5, 6, 7, 8, 9 e 10) mostram tendência da redução dos valores de $R$ e $\mathrm{H}$ durante o período seco para os três domínios estudados. 
Tabela 5. Médias dos valores de riqueza (R) e diversidade de Shannon (H) das UTOs de archeas em solo rizosférico e não rizosférico em floresta de eucalipto com 18 meses pós - plantio (Projeto Catas Altas I) na região do Vale do Rio Doce, Minas Gerais, Brasil.

\begin{tabular}{|c|c|c|c|c|c|}
\hline \multicolumn{6}{|c|}{ Médias dos Valores de Riqueza e Diversidade das UTOs de Archaeas do Solo - Catas Altas I ${ }^{1}$} \\
\hline \multirow{2}{*}{ Tratamento } & \multirow{2}{*}{ Amostragem $^{3}$} & \multicolumn{2}{|c|}{ Solo Rizosférico } & \multicolumn{2}{|c|}{ Solo Não Rizosférico } \\
\hline & & $\mathbf{R}$ & $\mathbf{H}$ & $\mathbf{R}$ & $\mathbf{H}$ \\
\hline \multirow{3}{*}{ Árvores aneladas } & Início Chuvoso & $20,5 a b$ & $3,020 \mathrm{AB}$ & $19,5 \mathrm{ab}$ & $2,954 \mathrm{AB}$ \\
\hline & Chuvoso & $20,5 a b$ & $3,017 \mathrm{AB}$ & $21,5 \mathrm{ab}$ & $3,061 \mathrm{AB}$ \\
\hline & Seco & $10 d$ & $2,303 \mathrm{D}$ & $14 \mathrm{~cd}$ & $2,636 \mathrm{C}$ \\
\hline \multirow{3}{*}{$\begin{array}{c}\text { Árvores não } \\
\text { aneladas }\end{array}$} & Início Chuvoso & $17 \mathrm{bc}$ & $2,831 \mathrm{BC}$ & $20,5 a b$ & $3,020 \mathrm{AB}$ \\
\hline & Chuvoso & $22 \mathrm{a}$ & $3,091 \mathrm{~A}$ & $19,5 a b$ & $2,967 \mathrm{AB}$ \\
\hline & Seco & $21,5 \mathrm{ab}$ & $2,068 \mathrm{AB}$ & $17,5 \mathrm{abc}$ & $2,858 \mathrm{ABC}$ \\
\hline
\end{tabular}

1/Valores de Riqueza (R) e Diversidade de Shannon (H). Médias dos valores de riqueza seguidas pela mesma letra minúscula e de diversidade pela mesma letra maiúscula não diferem pelo Teste $\mathrm{t}$ a 5\%. ㄴ 2 Árvores com 18 meses de crescimento. ${ }^{3 /}$ Amostragens: 12/10/12 (Início do Período Chuvoso); 16/12/12 (Período Chuvoso); 02/05/12 (Período Seco)

Tabela 6. Médias dos valores de riqueza (R) e diversidade de Shannon (H) das UTOs de archeas em solo rizosférico e não rizosférico em floresta de eucalipto com 72 meses pós - plantio (Serra do Pinho) na região do Vale do Rio Doce, Minas Gerais, Brasil.

Médias dos Valores de Riqueza e Diversidade das UTOs de Archaeas do Solo - Serra do Pinho²

\begin{tabular}{|c|c|c|c|c|c|}
\hline \multirow{2}{*}{ Tratamento } & \multirow{2}{*}{ Amostragem $^{3}$} & \multicolumn{2}{|c|}{ Solo Rizosférico } & \multicolumn{2}{|c|}{ Solo Não Rizosférico } \\
\hline & & $\mathbf{R}$ & H & $\mathbf{R}$ & H \\
\hline \multirow{3}{*}{ Árvores aneladas } & Início Chuvoso & $26,5 \mathrm{a}$ & $3,277 \mathrm{~A}$ & $25,5 a b$ & $3,237 \mathrm{AB}$ \\
\hline & Chuvoso & $20,5 \mathrm{bcd}$ & $3,012 \mathrm{BC}$ & 18 def & $2,888 \mathrm{CDE}$ \\
\hline & Seco & $15 \mathrm{fg}$ & $2,708 \mathrm{EF}$ & 15 efg & $2,736 \mathrm{DEF}$ \\
\hline \multirow{3}{*}{$\begin{array}{c}\text { Árvores não } \\
\text { aneladas }\end{array}$} & Início Chuvoso & 20 cdef & $2,984 \mathrm{BCD}$ & $23 \mathrm{abcd}$ & $3,132 \mathrm{ABC}$ \\
\hline & Chuvoso & $22,5 \mathrm{abcd}$ & $3,107 \mathrm{ABC}$ & $23,5 a b c$ & $3,156 \mathrm{AB}$ \\
\hline & Seco & $21,5 \mathrm{abcd}$ & $3,065 \mathrm{ABC}$ & $12,5 \mathrm{~g}$ & $2,525 \mathrm{~F}$ \\
\hline
\end{tabular}

1/Valores de Riqueza (R) e Diversidade de Shannon (H). Médias dos valores de riqueza seguidas pela mesma letra minúscula e de diversidade pela mesma letra maiúscula não diferem pelo Teste t a 5\%. ı Árvores com 72 meses de crescimento. 3/ Amostragens: 12/10/12 (Início do Período Chuvoso); 16/12/12 (Período Chuvoso); 02/05/12 (Período Seco)

Tabela 7. Médias dos valores de riqueza (R) e diversidade de Shannon (H) das UTOs de bactérias em solo rizosférico e não rizosférico em floresta de eucalipto com 18 meses pós - plantio (Projeto Catas Altas I) na região do Vale do Rio Doce, Minas Gerais, Brasil.

\begin{tabular}{|c|c|c|c|c|c|}
\hline \multicolumn{6}{|c|}{ Médias dos Valores de Riqueza e Diversidade das UTOs de Bacterias do Solo - Catas Altas I' } \\
\hline \multirow{2}{*}{ Tratamento } & \multirow{2}{*}{ Amostragem $^{3}$} & \multicolumn{2}{|c|}{ Solo Rizosférico } & \multicolumn{2}{|c|}{ Solo Não Rizosférico } \\
\hline & & $\mathbf{R}$ & $\mathbf{H}$ & $\mathbf{R}$ & $\mathbf{H}$ \\
\hline \multirow{3}{*}{$\begin{array}{l}\text { Árvores } \\
\text { aneladas }\end{array}$} & Início Chuvoso & $25 \mathrm{~b}$ & $3,215 \mathrm{AB}$ & $30,5 \mathrm{a}$ & $3,417 \mathrm{~A}$ \\
\hline & Chuvoso & $24,5 \mathrm{~b}$ & $3,198 \mathrm{AB}$ & $26 a b$ & $3,257 \mathrm{AB}$ \\
\hline & Seco & $30,5 \mathrm{~b}$ & $3,416 \mathrm{~A}$ & $15 d$ & $2,706 \mathrm{D}$ \\
\hline \multirow{3}{*}{$\begin{array}{c}\text { Árvores não } \\
\text { aneladas }\end{array}$} & Início Chuvoso & $26 a b$ & $3,257 \mathrm{AB}$ & $26 a b$ & $3,255 \mathrm{AB}$ \\
\hline & Chuvoso & $19 \mathrm{~cd}$ & $2,944 \mathrm{C}$ & $25 \mathrm{~b}$ & $3,215 \mathrm{AB}$ \\
\hline & Seco & $22,5 \mathrm{bc}$ & $3,107 \mathrm{BC}$ & $19 \mathrm{~cd}$ & $2,932 \mathrm{CD}$ \\
\hline
\end{tabular}

1/Valores de Riqueza (R) e Diversidade de Shannon (H). Médias dos valores de riqueza seguidas pela mesma letra minúscula e de diversidade pela mesma letra maiúscula não diferem pelo Teste t a 5\%. $\stackrel{2}{2}$ Árvores com 18 meses de crescimento. $\stackrel{3 \prime}{\prime}$ Amostragens: 12/10/12 (Início do Período Chuvoso); 16/12/12 (Período Chuvoso); 02/05/12 (Período Seco) 
Tabela 8. Médias dos valores de riqueza (R) e diversidade de Shannon (H) das UTOs de bactérias em solo rizosférico e não rizosférico em floresta de eucalipto com 72 meses pós - plantio (Projeto Serra do Pinho) na região do Vale do Rio Doce, Minas Gerais, Brasil.

\begin{tabular}{|c|c|c|c|c|c|}
\hline \multirow{2}{*}{ Tratamento } & \multirow{2}{*}{ Amostragem $^{3}$} & \multicolumn{2}{|c|}{ Solo Rizosférico } & \multicolumn{2}{|c|}{ Solo Não Rizosférico } \\
\hline & & $\mathbf{R}$ & $\mathbf{H}$ & $\mathbf{R}$ & $\mathbf{H}$ \\
\hline \multirow{3}{*}{$\begin{array}{l}\text { Árvores } \\
\text { aneladas }\end{array}$} & Início Chuvoso & $21,5 \mathrm{c}$ & $3,068 \mathrm{C}$ & $23 a b c$ & $3,134 \mathrm{ABC}$ \\
\hline & Chuvoso & $23 a b c$ & $3,132 \mathrm{ABC}$ & $26,5 a b$ & $3,277 \mathrm{AB}$ \\
\hline & Seco & $22 \mathrm{c}$ & $3,087 \mathrm{BC}$ & $27 a$ & $3,293 \mathrm{~A}$ \\
\hline \multirow{3}{*}{$\begin{array}{c}\text { Árvores não } \\
\text { aneladas }\end{array}$} & Início Chuvoso & $22,5 \mathrm{bc}$ & $3,113 \mathrm{ABC}$ & $23 a b c$ & $3,134 \mathrm{ABC}$ \\
\hline & Chuvoso & $19,5 \mathrm{c}$ & $2,967 \mathrm{C}$ & $27 a$ & $3,296 \mathrm{~A}$ \\
\hline & Seco & $23 a b c$ & $3,134 \mathrm{ABC}$ & $21,5 \mathrm{c}$ & $3,061 \mathrm{C}$ \\
\hline
\end{tabular}

1/Valores de Riqueza (R) e Diversidade de Shannon (H). Médias dos valores de riqueza seguidas pela mesma letra minúscula e de diversidade pela mesma letra maiúscula não diferem pelo Teste $\mathrm{t}$ a 5\%. ㄴ 2 Árvores com 72 meses de crescimento. ${ }^{3 /}$ Amostragens: 12/10/12 (Início do Período Chuvoso); 16/12/12 (Período Chuvoso); 02/05/12 (Período Seco)

Tabela 9. Médias dos valores de riqueza (R) e diversidade de Shannon (H) das UTOs de fungos em solo rizosférico e não rizosférico em floresta de eucalipto com 18 meses pós - plantio (Projeto Catas Altas I) na região do Vale do Rio Doce, Minas Gerais, Brasil.

Médias dos Valores de Riqueza e Diversidade das UTOs de Fungos do Solo - Catas Altas I ${ }^{1}$

\begin{tabular}{|c|c|c|c|c|c|}
\hline \multirow{2}{*}{ Tratamento } & \multirow{2}{*}{ Amostragem $^{3}$} & \multicolumn{2}{|c|}{ Solo Rizosférico } & \multicolumn{2}{|c|}{ Solo Não Rizosférico } \\
\hline & & $\mathbf{R}$ & H & $\mathbf{R}$ & H \\
\hline \multirow{3}{*}{$\begin{array}{l}\text { Árvores } \\
\text { aneladas }\end{array}$} & Início Chuvoso & $17,5 a b c$ & $2,852 \mathrm{AB}$ & $19,5 a b$ & $2,995 \mathrm{AB}$ \\
\hline & Chuvoso & $22 \mathrm{a}$ & $3,087 \mathrm{~A}$ & $18 a b$ & $2,876 \mathrm{AB}$ \\
\hline & Seco & $16,5 \mathrm{abc}$ & $2,799 \mathrm{ABC}$ & $13,5 \mathrm{bc}$ & $2,585 \mathrm{BC}$ \\
\hline \multirow{3}{*}{$\begin{array}{c}\text { Árvores não } \\
\text { aneladas }\end{array}$} & Início Chuvoso & $18 a b$ & $2,913 \mathrm{AB}$ & $22 \mathrm{a}$ & $3,087 \mathrm{~A}$ \\
\hline & Chuvoso & $19 a b$ & $2,943 A B$ & $20,5 \mathrm{a}$ & $3,012 \mathrm{AB}$ \\
\hline & Seco & $11 \mathrm{c}$ & $2,327 \mathrm{C}$ & $16 \mathrm{abc}$ & $2,770 \mathrm{ABC}$ \\
\hline
\end{tabular}

1 Valores de Riqueza (R) e Diversidade de Shannon (H). Médias dos valores de riqueza seguidas pela mesma letra minúscula e de diversidade pela mesma letra maiúscula não diferem pelo Teste t a 5\%. ı Árvores com 18 meses de crescimento. 3/ Amostragens: 12/10/12 (Início do Período Chuvoso); 16/12/12 (Período Chuvoso); 02/05/12 (Período Seco)

Tabela 10. Médias dos valores de riqueza (R) e diversidade de Shannon (H) das UTOs de fungos em solo rizosférico e não rizosférico em floresta de eucalipto com 72 meses pós - plantio (Projeto Serra do Pinho) na região do Vale do Rio Doce, Minas Gerais, Brasil.

\begin{tabular}{|c|c|c|c|c|c|}
\hline \multicolumn{6}{|c|}{ Médias dos Valores de Riqueza e Diversidade das UTOs de Fungos do Solo - Serra do Pinho² } \\
\hline \multirow{2}{*}{ Tratamento } & \multirow{2}{*}{ Amostragem ${ }^{3}$} & \multicolumn{2}{|c|}{ Solo Rizosférico } & \multicolumn{2}{|c|}{ Solo Não Rizosférico } \\
\hline & & $\mathbf{R}$ & $\mathbf{H}$ & $\mathbf{R}$ & $\mathbf{H}$ \\
\hline \multirow{3}{*}{ Árvores aneladas } & Início Chuvoso & $17 \mathrm{abc}$ & $2,831 \mathrm{AB}$ & $19 \mathrm{ab}$ & $2,994 \mathrm{AB}$ \\
\hline & Chuvoso & $24 \mathrm{a}$ & $3,177 \mathrm{~A}$ & $21 \mathrm{ab}$ & $3,034 \mathrm{AB}$ \\
\hline & Seco & $16 \mathrm{bc}$ & $2,740 \mathrm{BC}$ & $15,5 b c$ & $2,674 \mathrm{BC}$ \\
\hline \multirow{3}{*}{$\begin{array}{c}\text { Árvores não } \\
\text { aneladas }\end{array}$} & Início Chuvoso & $19 a b$ & $2,994 A B$ & $17,5 a b$ & $2,852 A B$ \\
\hline & Chuvoso & $21 a b$ & $3,045 A B$ & $20,5 a b$ & $3,020 \mathrm{AB}$ \\
\hline & Seco & $10 \mathrm{c}$ & $2,297 \mathrm{C}$ & $19 a b$ & $2,994 \mathrm{AB}$ \\
\hline
\end{tabular}

1/Valores de Riqueza (R) e Diversidade de Shannon $(H)$. Médias dos valores de riqueza seguidas pela mesma letra minúscula e de diversidade pela mesma letra maiúscula não diferem pelo Teste $\mathrm{t}$ a 5\%. ㄴ Árvores com 72 meses de crescimento. ${ }^{3 /}$ Amostragens: 12/10/12 (Início do Período Chuvoso); 16/12/12 (Período Chuvoso); 02/05/12 (Período Seco). 
A pouca distinção entre as comunidades de archaeas, bactérias e fungos ao entorno das árvores aneladas e não aneladas (Figuras 2, 3 e 4) demonstram que mesmo considerando a realização do anelamento, não havendo no período do experimento a reconstituição da porção anelada, as reservas de carboidratos encontrados nas raízes foram suficientes para manter a atividade microbiana, considerando a ausência de plantas no sub-bosque.

Binkley et al. (2006) estudando os efeitos do anelamento em florestas de eucalipto na região costeira do estado da Bahia, Brasil, verificou que, mesmo após cinco meses após o anelamento das plantas, houve pouca redução da biomassa de raízes finas vivas. Este potencial de manutenção das raízes finas após o anelamento e a consequente manutenção do fluxo de exsudatos na região rizosférica, concorre como possível causa da pequena alteração no perfil das comunidades microbianas neste experimento.

A presença de UTOs dominantes de arqueas, bactérias e fungos ao longo do período avaliado (Figuras 2, 3 e 4), bem como a presença de uma diversa gama de UTOs características de cada época indicam que a diversidade microbiana nesse habitat apresenta pouca alteração ao longo do crescimento da planta. Modelos desenvolvidos com base em dados ambientais mostram que o aumento da complexidade leva a uma maior estabilidade em comunidades diversas, onde a combinação de interações antagônicas e mutualísticas pode estabilizar a dinâmica populacional (Mougi \& Kondoh, 2012).

A variação dos perfis de DGGE dentro de um gradiente sazonal (Figuras 2, 3 e 4) para os três domínios estudados mostra que a sazonalidade é o principal determinante da comunidade microbiana nos solos de florestas plantadas de eucalipto. Estudos similares relatam que a sazonalidade é o principal determinante da variação do perfil das comunidades microbianas em solos florestais (Brant et al., 2006; Li et al., 2005; Feng et al., 2009; Chen et al., 2010; Liu et al., 2010). Em florestas de eucalipto de regiões subtropicais a composição da comunidade bacteriana do solo bem como o perfil de utilização de substratos também apresentam respostas sazonais (Liu et al., 2010).

O menor efeito do anelamento sobre a estrutura da comunidade microbiana quando comparado ao efeito da sazonalidade (Figuras 2, 3 e 4) pode ser explicado pela regeneração de raízes finas, disponibilização das reservas de carboidratos para a região da rizosfera e pela decomposição das raízes mortas após o anelamento. Estudos relatam que árvores de eucalipto aneladas ainda são capazes de produzir novas raízes bem como produzir alguns exsudatos radiculares (Binkley et al. 2006; Zeller et al. 2008; Chen et al. 2010; Wu et al., 2011).

A pequena variação nos índices de riqueza e diversidade das comunidades de archeas (Tabelas 5 e 6), bactérias (Tabelas 7 e 8 ) e fungos (Tabelas 9 e 10) encontrados nos solos em duas fases de crescimento da planta indicam que o ciclo de crescimento de florestas de eucalipto não influencia negativamente a diversidade microbiana do solo, sendo clara a tendência de redução dos índices apenas em função da época de coleta. Nesse sentido, os resultados corroboram estudos da comunidade microbiana por PFLA (análise de perfil de ácidos graxos), em solos sob florestas de eucalipto na região subtropical da China, em que os autores comprovaram que a diversidade é influenciada por fatores sazonais e pela umidade do solo, sendo observada pouca variabilidade entre as fases de crescimento da planta (Cao et al, 2010).

\section{CONCLUSÃO}

A sazonalidade, em maior escala, e o aporte de fotoassimilados para a rizosfera determinam a estrutura das comunidades microbianas em solos de florestas de eucalipto na região do Vale do Rio Doce, Minas Gerais, Brasil.

A análise dos índices derivados da PCR-DGGE permitiu inferir a capacidade da planta de regular o fluxo de fotoassimilados para a rizosfera e, consequentemente, da estrutura da comunidade microbiana rizosférica durante o período avaliado. 


\section{REFERÊNCIAS}

Bais, H. P., Weir, T. L., Perry, L. G., Gilroy, S., \& Vivanco, J. M. (2006). The role of root exudates in rhizosphere interactions with plants and other organisms. Annual Review of Plant Biology, 57(1), 233266. PMid:16669762. http://dx.doi.org/10.1146/annurev.arplant.57.032905.105159.

Barret, M., Morrissey, J. P., \& O'Gara, F. (2011). Functional genomics analysis of plant growth-promoting rhizobacterial traits involved in rhizosphere competence. Biology and Fertility of Soils, 47(7), 729-743. http://dx.doi.org/10.1007/s00374-011-0605-x.

Binkley, D., Stape, J. L., Takahashi, E. N., \& Ryan, M. G. (2006). Tree-girdling to separate root and heterotrophic respiration in two Eucalyptus stands in Brazil. Oecologia, 148(3), 447-454. PMid:16496179. http://dx.doi.org/10.1007/s00442-006-0383-6.

Brant, J. B., Myrold, D. D., \& Sulzman, E. W. (2006). Root controls on soil microbial community structure in forest soils. Oecologia, 148(4), 650-659. PMid:16547734. http://dx.doi.org/10.1007/s00442-0060402-7.

Buckley, D. H., \& Schmidt, T. M. (2002). Exploring the biodiversity of soil: a microbial rainforest., In J. T. Staley \& A. L. Reysenbach (Eds.), Biodiversity of microbial life (pp. 183-208). New York: Wiley-Liss.

Cao, Y. S., Fu, S. L., Zou, X. M., Cao, H. L., Shao, Y. H., \& Zhou, L. X. (2010). Soil microbial community composition under Eucalyptus plantations of different age in subtropical China. European Journal of Soil Biology, 46(2), 128-135. http://dx.doi.org/10.1016/j.ejsobi.2009.12.006.

Chen, D. M., Zhang, Y., Lin, Y. B., Zhu, W. X., \& Fu, S. L. (2010). Changes in belowground carbon in Acacia crassicarpa and Eucalyptus urophylla plantations after tree girdling. Plant and Soil, 326(1-2), 123-135. http://dx.doi.org/10.1007/s11104-009-9986-0.

Compant, S., Van Der Heijden, M. G. A., \& Sessitsch, A. (2010). Climate change effects on beneficial plant-microorganism interactions. FEMS Microbiology Ecology, 73(2), 197-214. PMid:20528987. http://dx.doi.org/10.1111/j.1574-6941.2010.00900.x.

Daniel, R. (2005). The metagenomics of soil. Nature reviews. Microbiology, 3(6), 470-478. PMid:15931165.

Deng, W. D., Wanapat, M. M., Ma, S., Chen, J., Xi, D., He, T., Yang, Z., \& Mao, H. (2007). Phylogenetic analysis of 16S rDNA sequences manifest rumen bacterial diversity in Gayals (Bos frontalis) fed fresh bamboo leaves and twigs (Sinarumdinaria). Asian-Australasian Journal of Animal Sciences, 20(7), 10571066. http://dx.doi.org/10.5713/ajas.2007.1057.

Favier, C. F., Vaughan, E. E., De Vos, W. M., \& Akkermans, A. D. L. (2002). Molecular monitoring of succession of bacterial communities in human neonates. Applied and Environmental Microbiology, 68(1), 219-226. PMid:11772630. http://dx.doi.org/10.1128/AEM.68.1.219-226.2002.

Feng, W. T., Zou, X. M., \& Schaefer, D. (2009). Above- and belowground carbon inputs affect seasonal variations of soil microbial biomass in a subtropical monsoon forest of southwest China. Soil Biology \& Biochemistry, 41(5), 978-983. http://dx.doi.org/10.1016/j.soilbio.2008.10.002.

Fontaine, S., Bardoux, G., Benest, D., Verdier, B., Mariotti, A., \& Abbadie, L. (2004). Mechanisms of the priming effect in a savannah soil amended with cellulose. Soil Science Society of America Journal, 68(1), 125-131. http://dx.doi.org/10.2136/sssaj2004.1250.

Garbeva, P., van Veen, J. A., \& van Elsas, J. D. (2004). Microbial diversity in soil: selection microbial populations by plant and soil type and implications for disease suppressiveness. Annual Review of Phytopathology, 42(1), 243-270. PMid:15283667. http://dx.doi.org/10.1146/annurev.phyto.42.012604.135455.

Hammer, Ø. (2012). PAST Paleontological Statistics version 2.16. Reference Manual. Oslo: Natural History Museum, University of Oslo Norway.

Högberg, P., Nordgren, A., Buchmann, N., Taylor, A. F., Ekblad, A., Högberg, M. N., Nyberg, G., OttossonLöfvenius, M., \& Read, D. J. (2001). Large-scale forest girdling shows that current photosynthesis drives soil respiration. Nature, 411(6839), 789-792. http://dx.doi.org/10.1038/35081058.

Högberg, P., \& Read, D. J. (2006). Towards a more plant physiological perspective on soil ecology. Trends in Ecology \& Evolution, 21(10), 548-554. PMid:16806577. http://dx.doi.org/10.1016/j.tree.2006.06.004.

Instituto Brasileiro de Árvores - IBÁ. (2019). Sumário executivo da indústria brasileira de árvores: relatório 2019 (80 p.). Brasília: IBÁ. Recuperado em 27 de outubro de 2019, de https://iba.org/datafiles/publicacoes/relatorios/iba-relatorioanual2019.pdf

Jackson, L. E., Burger, M., \& Cavagnaro, T. R. (2008). Roots, nitrogen transformations, and ecosystem services. Annual Review of Plant Biology, 59(1), 341-363. PMid:18444903. http://dx.doi.org/10.1146/annurev.arplant.59.032607.092932. 
Jurgens, G., Lindstrom, K., \& Saano, A. (1997). Novel group within the kingdom Crenarchaeota from boreal forest soil. Applied and Environmental Microbiology, 63(2), 803-805. PMid:9023962. http://dx.doi.org/10.1128/AEM.63.2.803-805.1997.

Lane, D. J., Pace, B., Olsen, G. J., Stahl, D. A., Sogin, M. L., \& Pace, N. R. (1985). Rapid determination of 165 ribosomal RNA sequences for phylogenetic analyses. Proceedings of the National Academy of Sciences of the United States of America, 82(20), 6955-6959. PMid:2413450. http://dx.doi.org/10.1073/pnas.82.20.6955.

Li, Y. Q., Xu, M., Zou, X. M., \& Xia, Y. (2005). Soil $\mathrm{CO}_{2}$ efflux and fungal and bacterial biomass in a plantation and a secondary forest in wet tropics in Puerto Rico. Plant and Soil, 268(1), 151-160. http://dx.doi.org/10.1007/s11104-004-0234-3.

Liu, Z. F., Fu, B. J., Zheng, X. X., \& Liu, G. H. (2010). Plant biomass, soil water content and soil N:P ratio regulating soil microbial functional diversity in a temperate steppe: a regional scale study. Soil Biology \& Biochemistry, 42(3), 445-450. http://dx.doi.org/10.1016/j.soilbio.2009.11.027.

May, L. A., Smiley, B., \& Schmidt, M. G. (2001). Comparative denaturing gradient gel electrophoresis analysis of fungal communities associated with whole plant corn silage. Canadian Journal of Microbiology, 47(9), 829-841. PMid:11683465. http://dx.doi.org/10.1139/w01-086.

Mougi, A., \& Kondoh, M. (2012). Diversity of interaction types and ecological community stability. Science, 337(6092), 349-351. PMid:22822151. http://dx.doi.org/10.1126/science.1220529.

Nübel, U., Engelen, B., Felske, A., Snaidr, J., Wieshuber, A., Amann, R. I., Ludwig, W., \& Backhaus, H. (1996). Sequence heterogeneities of genes encoding 16S rRNAs in Paenibacillus polymyxa detected by temperature gradient gel electrophoresis. Journal of Bacteriology, 178(19), 5636-5643. http://dx.doi.org/10.1128/jb.178.19.5636-5643.1996.

Oros-Sichler, M., Gomes, N. C. M., Neuber, G., \& Smalla, K. (2006). A new seminested PCR protocol to amplify large 18S rRNA gene fragments for PCRDGGE analysis of soil fungal communities. Journal of Microbiological Methods, 65(1), 63-75. PMid:16102860.

Rasche, F., Knapp, D., Kaiser, C., Koranda, M., Kitzler, B., Zechmeister-Boltenstern, S., Richter, A., \& Sessitsch, A. (2011). Seasonality and resource availability control bacterial and archaeal communities in soils of a temperate beech forest. The ISME Journal, 5(3), 389-402. PMid:20882059. http://dx.doi.org/10.1038/ismej.2010.138.

Raskin, L., Stromley, J. M., Rittmann, B. E., \& Stahl, D. A. (1994). Groupspecific 16 S rRNA hybridization probes to describe natural communities of methanogens. Applied and Environmental Microbiology, 60(4), 1232-1240. PMid:7517128. http://dx.doi.org/10.1128/AEM.60.4.1232-1240.1994.

Schloss, P. D., Westcott, S. L., Ryabin, T., Hall, J. R., Hartmann, M., Hollister, E. B., Lesniewski, R. A., Oakley, B. B., Parks, D. H., Robinson, C. J., Sahl, J. W., Stres, B., Thallinger, G. G., Van Horn, D. J., \& Weber, C. F. (2009). Introducing mothur: open-source, platform-independent, communitysupported software for describing and comparing microbial communities. Applied and Environmental Microbiology, 75(23), 7537-7541. PMid:19801464. http://dx.doi.org/10.1128/AEM.01541-09.

Silva, F. A. S. (2012). Assistat versão 7.6 beta. Assistência estatística. Campina Grande: UFCG. Registro INPI: 0004051-2. DEACG-CTRN-UFCG.

Silverio, F. O., Barbosa, L. C. A., Maltha, C. R. A., Silvestre, A. J. D., Pilo-Veloso, D., \& Gomide, J. L. (2007). Characterization of lipophilic wood extractives from clones of Eucalyptus urograndis cultivate in Brazil. BioResources, 2(2), 157-168. http://dx.doi.org/10.15376/biores.2.2.157-168.

Stape, J. L., Binkley, D., Ryan, M. G., Fonseca, S., Loos, R. A., Takahashi, E. N., Silva, C. R., Silva, S. R., Hakamada, R. E., Ferreira, J. M. A., Lima, A. M. N., Gava, J. L., Leite, F. P., Andrade, H. B., Alves, J. M., Silva, G. G. C., \& Azevedo, M. R. (2010). The Brazil Eucalyptus Potential Productivity Project: influence of water, nutrients and stand uniformity on wood production. Forest Ecology and Management, 259(9), 1684-1694. http://dx.doi.org/10.1016/j.foreco.2010.01.012.

Vainio, E. J., \& Hantula, J. (2000). Direct analysis of wood-inhabiting fungi using denaturing gradient gel electrophoresis of amplified ribosomal DNA. Mycological Research, 104(8), 927-936. http://dx.doi.org/10.1017/S0953756200002471.

Wardle, D. A. (1992). A comparative assessment of factors which influence microbial biomass carbon and nitrogen levels in soil. Biological Reviews of the Cambridge Philosophical Society, 67(3), 321-358. http://dx.doi.org/10.1111/j.1469-185X.1992.tb00728.x.

Wu, J., Liu, Z., Wang, X., Sun, Y., Zhou, L., Lin, Y., \& Fu, S. (2011). Effects of understory removal and tree girdling on soil microbial community composition and litter decomposition in two Eucalyptus 
plantations in South China. Functional Ecology, 25(4), 921-931. http://dx.doi.org/10.1111/j.13652435.2011.01845.x.

Yarwood, S. A., Myrold, D. D., \& Högberg, M. N. (2009). Termination of belowground C allocation by trees alters soil fungal and bacterial communities in a boreal forest. FEMS Microbiology Ecology, 70(1), 151162. PMid:19656196. http://dx.doi.org/10.1111/j.1574-6941.2009.00733.x.

Yin, H., Wheeler, E., \& Phillips, R. P. (2014). Root-induced changes in nutrient cycling in forests depend on exudation rates. Soil Biology \& Biochemistry, 78, 213-221. http://dx.doi.org/10.1016/j.soilbio.2014.07.022.

Zeller, B., Liu, J. X., Buchmann, N., \& Richter, A. (2008). Tree girdling increases soil N mineralization in two spruce stands. Soil Biology \& Biochemistry, 40(5), 1155-1166. http://dx.doi.org/10.1016/j.soilbio.2007.12.009.

Contribuição dos Autores: JCD, PSBM, MNVO, MHRF, RC e ACB: Curadoria de Dados, Análise Formal, Investigação, Metodologia, Administração do Projeto, Recursos, Supervisão, Escrita - Primeira Redação, Escrita Revisão e Edição. 